\title{
Evaluating "Starting Well," the Scottish National Demonstration Project for Child Health: Outcomes at Six Months
}

\author{
Jonathan L. Shute ${ }^{1,3}$ and Ken Judge ${ }^{2}$
}

This paper presents early findings from the evaluation of Starting Well, an intensive home visiting program aimed at improving the health of pre-school children in disadvantaged areas of Glasgow, Scotland. Using a quasi-experimental design, detailed survey, observation and interview data were collected on a cohort of 213 intervention and 146 comparison families over the first six months of the child's life. After controlling for relevant background characteristics, multivariate regression analysis revealed higher child dental registration rates and lower rates of maternal depressive symptoms in the intervention cohort. Findings are interpreted as positive evidence of early program impact. Implications, limitations and future plans for analysis are discussed.

Editors' Strategic Implications: Starting Well draws on elements of an Australian parent education program and an American home visitation model. The authors demonstrate how the program implementation, research questions, and measurement are designed to fit their Glasgow population and the Scottish public health system. Their quasi-experimental data suggest that this primary prevention program is a promising strategy for improving maternal and child health outcomes.

KEY WORDS: home visiting; evaluation; post natal depression; home environment; dental registration.

\footnotetext{
${ }^{1}$ School of Law, University of Manchester, Manchester.

${ }^{2}$ Health Promotion Policy Unit, Public Health and Health Policy Section, Division of Community Based Sciences, University of Glasgow, Glasgow.

${ }^{3}$ Address correspondence to Jon L. Shute, School of Law, University of Manchester, Room 4.50, Williamson Building, Manchester M13 9PL, United Kingdom; e-mail: jon.shute@manchester.ac.uk.
} 


\section{INTRODUCTION}

\section{Home Visiting and Child Health}

International evidence suggests that home-based preventive interventions delivered by trained health professionals can improve a range of outcomes for vulnerable pre-school children (Bull, McCormick, Swann \& Mulvihill, 2004; Elkan et al., 2000). Most studies are too small to detect direct improvements in child health (e.g., lower morbidity and/or mortality rates) but show improvements in related factors, for example, quality of the home environment (Shapiro, 1995), detection and management of postnatal depression (Ray \& Hodnett, 1997) and improved rates of breastfeeding (Kitzman et al., 1997). In addition, long-term cohort studies show the benefits of home visiting to be diverse and enduring for both mother and child (Olds et al., 1997, 1998). In this paper we present findings from the evaluation of a new Scottish home visiting program that are suggestive of beneficial early impact on outcomes related to child and maternal health.

\section{The Starting Well National Demonstration Project for Child Health}

Starting Well is an evidence-based home visiting program commissioned by the Scottish Executive Health Department in late 2000 as part of its National Demonstration Projects program (Scottish Executive, 2003). As described by Ross and de Caestecker (this issue), the program is active in two similarly disadvantaged communities in the city of Glasgow and engages all families with newborn infants via a team of trained health professionals and lay workers who deliver an intensive home-based service that augments routine provision. Key service innovations include topic-specific initiatives (home safety, encouraging and modeling play), enhanced support for minority ethnic families and the delivery of a validated parenting skills program (the Positive Parenting Program; Sanders, 1999). In addition to the home visiting program, the project engages each community by attempting to build links between existing pre-school agencies and by developing new resources. The overall aim is to improve child health statistics that are among the worst in Western Europe (National Children's Homes Scotland, 2002).

\section{Evaluating Starting Well}

The Scottish Executive commissioned an external (independent) evaluation of Starting Well in early 2001. In evaluation terms, Starting Well is a comprehensive community initiative (Connell \& Kubisch, 1998) and has properties that make it challenging to evaluate. For example, it has been subject to continuous and significant development over time; it has multiple foci (child, family, community); and, despite envisioning longer-term impacts, has a relatively short (three year) 
evaluation period. In these circumstances, no one evaluation methodology could be adequate and accordingly, there are several complementary strands concentrating on theory, process, and outcome.

The evaluation uses a 'Theory of Change' approach (Fulbright-Anderson, Kubisch, \& Connell, 1998) to elicit stakeholders' views of how and why the intervention is being implemented and to capture their expectations of program impact. This approach can help to sharpen thinking regarding implementation, identify additional questions for evaluators and, by describing what happened, when and with what intention, may help reduce problems of causal attribution of impact (see Judge \& Bauld, 2001; Judge \& Mackenzie, 2002).

Process is being explored via three discrete pieces of qualitative work, each examining key components of the intervention. These are: case-studies of the functional relationship between mother and health visitor; the process of constituting and developing the staff team of professionals and lay workers; and the process by which locally identified health needs influence local and higher-level planning decisions.

Outcomes are being assessed via a quasi-experimental cohort study comparing the health and development of intervention children over the first eighteen months of life with a group of families receiving statutory health visiting in a demographically similar part of the city. All participating children are assessed on three occasions (immediately after birth, then at six and eighteen months) using a combination of mother-report questionnaires, family observation in the home and structured interviews with the mother. While the intervention aims to promote positive change at various levels (child, family and community), this evaluation component aims to explore impact primarily at the level of the child while controlling for potential confounding variables (e.g., maternal and household characteristics). In addition to testing for overall intervention effects on a range of outcomes, sub-group analyses will be important for determining the characteristics of the families that derive most benefit. Finally, following an ecological model of health, findings from this study component will be interpreted in the light of a comparative study of the material and social characteristics of each intervention area.

\section{Assessing Early Impact}

This paper presents early findings from the quasi-experimental study. Controlling for potential confounding variables, we assess the evidence for intervention effects over the first six months of the child's life using three diverse outcome measures. Two of these-quality of the home environment and extent of maternal depressive symptoms - are chosen firstly, because of their proven association with later child cognitive and emotional development (Bradley, 1993; Murray \& Cooper, 1997) and secondly, because well-validated instruments exist to measure 
Table I. Total Number of Births and Opt-ins

\begin{tabular}{lccr}
\hline & Comparison area & Intervention area & All \\
\hline Population (total births) & 661 & 604 & 1265 \\
Sample (total opt-ins) & 260 & 367 & 627 \\
Sample as \% of population & 39 & 61 & 50 \\
\hline
\end{tabular}

them (Bradley \& Caldwell, 1988; Cox, Holden, \& Sagovsky, 1987). The third outcome-the child's dental registration status as reported by the mother-was chosen as an indicator of oral health, an area in which the program is trying to promote positive change. In addition to testing for intervention effects, we also examine the important subsidiary question of which other factors are statistically significantly associated with these outcomes.

\section{METHODS}

\section{Target Populations}

The intervention population was defined as all births visited by Starting Well health visitors between 01/06/01 and 31/06/02 within the project's strict geographical boundaries. The comparison population was defined as all births ${ }^{3}$ assigned to health-visiting teams working in the Northern Local Health Care Co-operative (a primary care administrative unit) over the same time period. Comparison area health visitors are 'attached' to particular General Practitioner surgeries and only visit families that are registered at that surgery; this means that there is a strong but not defining geographic focus to their work. Consent to evaluation was lower than expected in the comparison area and consequently recruitment was extended to a further two health visiting teams in the west of Glasgow between 01/04/02 and 31/06/02. The numbers of births and opt-ins are shown in Table I.

Around $50 \%$ of eligible families opted into the evaluation, proportionally more so from the intervention area(s). This is perhaps unsurprising given the implicit incentive of receiving the enhanced service.

\section{Procedure}

Each opt-in parent/family received a baseline postal survey. This was sent out as soon as the consent form was received from the attending health visitor, in most

\footnotetext{
${ }^{3}$ As part of the UK's immigration and asylum policy, several hundred families of asylum-seekers were 'dispersed' (temporarily settled) to the area covered by the Northern LHCC during the study recruitment period. Births to these families could not be included due to variations in the developing health visiting service and to lack of interpreting support.
} 
Table II. Fieldwork Returns, Baseline and Six-month Data Collection

\begin{tabular}{lccccc}
\hline & \multicolumn{2}{c}{ Cohort $(n=)$} & & \multicolumn{2}{c}{$\begin{array}{c}\text { Totals as percentage } \\
\text { of . . . }\end{array}$} \\
\cline { 2 - 3 } & Comparison & Intervention & Total & $\begin{array}{c}\text { Sample } \\
(n=627)\end{array}$ & $\begin{array}{c}\text { Population } \\
(n=1265)\end{array}$ \\
\hline Baseline survey returns & 180 & 267 & 447 & 71.3 & 35.3 \\
6-month survey returns & 198 & 292 & 490 & 78.2 & 38.7 \\
6-month HOME interviews & 192 & 301 & 493 & 78.6 & 39.0 \\
$\begin{array}{l}\text { Participants completing full } \\
\text { baseline + 6-month assessments }\end{array}$ & 146 & 213 & 359 & 57.3 & 28.4 \\
\hline
\end{tabular}

cases, within two months of the child's birth. The survey covered: background maternal, household and area characteristics; maternal mental health and health behavior; and attitudes towards parenting and current health-visiting service. Interpreters were made available to assist participants with no or limited English ( $n=21)$ and completed surveys were returned using a pre-paid envelope. Participants with overdue surveys were followed up by letter and phone. Further surveys were sent out to each participant when their child was six months old. Content focused on mother-reported child outcomes and updates of maternal health, support and attitudes to the health visiting service.

In addition, each participant that could be contacted at six months received a home visit from one of three trained research nurses who administered the Infant-Toddler HOME Inventory (Home Observation and Measurement of the Environment; Bradley \& Caldwell, 1979). The average interview lasted around one hour. At the end of the interview, the nurse administered several additional survey instruments (e.g., the Edinburgh Postnatal Depression Scale) and retrieved any incomplete or unsent postal surveys. Again, interpreters were available for non-English speakers.

Returns for the first two phases of fieldwork are shown in Table II. Contact by research nurses at six months produced a better survey return rate than baseline postal methods, while similar fieldwork completion rates were observed at both assessments across cohorts. The populations from which the cohorts are drawn are residentially mobile and attrition of participants has been a constant problem; at the time of writing, $73(11.6 \%)$ of the original sample have either voluntarily withdrawn from the study $(n=26)$ or have moved without leaving a forwarding address $(n=47)$.

All data were collated and stored securely at the study offices, before being coded and entered. A proportion of the cohort $(n=359)$ had completed full baseline and six-month assessments while a further 93 had not been seen at baseline but had completed a brief retrospective survey at six months, covering basic child, maternal and household characteristics. Richness of data was considered to be more important than participant numbers and so the focus of this paper is the smaller but more detailed dataset $(n=359)$. 
Table III. Sample Characteristics at Baseline: Comparison of Proportions

\begin{tabular}{|c|c|c|c|c|c|}
\hline \multirow[b]{2}{*}{ Variable } & \multicolumn{2}{|c|}{ Comparison } & \multicolumn{2}{|c|}{ Intervention } & \multirow[b]{2}{*}{$p$} \\
\hline & $n$ & $\%$ & $n$ & $\%$ & \\
\hline Male & 79 & 54.1 & 106 & 49.8 & .42 \\
\hline Low birth weight $(<2500 \mathrm{~g})$ & 15 & 10.3 & 20 & 9.4 & .78 \\
\hline First-time mothers & 72 & 49.3 & 105 & 49.3 & - \\
\hline Single-parents & 18 & 12.3 & 25 & 11.7 & .87 \\
\hline Minority Ethnic mother & 0 & 0 & 34 & 16 & $<.001$ \\
\hline Mother smokes & 59 & 40.4 & 72 & 33.8 & .20 \\
\hline Mother has no qualifications & 26 & 17.8 & 52 & 24.4 & .14 \\
\hline No car in household & 55 & 37.7 & 92 & 43.2 & .30 \\
\hline Not homeowner & 75 & 51.4 & 134 & 62.9 & .03 \\
\hline Workless households & 39 & 36.7 & 77 & 36.2 & .06 \\
\hline Higher income households & 72 & 49.3 & 59 & 27.7 & $<.001$ \\
\hline
\end{tabular}

Note. the large number of statistical comparisons made in Tables III and IV increase the chances of type I (false-positive) errors. The advised alpha level for a statistically significant difference is therefore $0.05 /$ number of comparisons $=0.05 / 16=0.003$.

\section{Sample Characteristics}

Tables III and IV comparatively describe key characteristics of these subset of participants. The cohorts are similar in terms of basic birth-relevant child and maternal characteristics; there are no significant differences in the proportion of males, low birth weight children and first time mothers. The mean gestation and mother's age are also very similar. Slightly, but not significantly, more comparison area mothers smoked at baseline. Smoking prevalence is higher than the Greater Glasgow NHS Board average of 27.4\% (National Health Service Scotland, 2001).

The proportion of minority ethnic participants is significantly greater in the intervention area. This reflects differences in the ethnic composition of the two intervention areas; one is homogeneous and predominantly white Scottish, the other, having a significant and well-established Scottish Asian community (mainly first, second and third generation Pakistani and Indian Muslims). Just over two (2.2) percent of all households in the city are headed by people of this ethnic background (General Register Office (Scotland), 2003).

Table IV. Sample Characteristics at Baseline: Comparison of Means

\begin{tabular}{|c|c|c|c|c|c|}
\hline \multirow[b]{2}{*}{ Variable } & \multicolumn{2}{|c|}{$\begin{array}{l}\text { Comparison } \\
(n=146)\end{array}$} & \multicolumn{2}{|c|}{$\begin{array}{l}\text { Intervention } \\
(n=213)\end{array}$} & \multirow[b]{2}{*}{$p$} \\
\hline & Mean & $S D$ & Mean & $S D$ & \\
\hline Gestation period (weeks) & 39.2 & 2.1 & 39.1 & 2.1 & .66 \\
\hline Mother's age (years) & 28.7 & 7 & 27.8 & 6.4 & .19 \\
\hline Mother's self-esteem score & 20.9 & 4.2 & 21.1 & 4.7 & 69 \\
\hline Number of children in household & 1.95 & 1.12 & 1.83 & 1.08 & .34 \\
\hline
\end{tabular}


The remaining statistics in Table III are derived from UK decennial census questions adapted for the baseline survey and are frequently used to index deprivation. They make two broad points: the first is that both cohorts are disadvantaged; a sizeable proportion of women are single parents, have no education or vocational qualifications, rent public housing, do not have access to a car and live in workless households. The second point is that, on virtually every measure, the intervention cohort is more disadvantaged, significantly so in terms of the proportion of higher income households. Compared with selected census statistics for Glasgow City (General Register Office (Scotland), 2003), the cohorts are broadly representative with regards to the percentage of households headed by lone parents (Glasgow $10.28 \%)$ and the percentage of non-homeowners $(51.46 \%)$ but considerably more deprived with regard to the percentage of workless households $(9.37 \%)$.

\section{Measures}

\section{Outcome Variables}

Three measures relating to child health were chosen as outcomes. The first of these is derived from the Infant/Toddler version of the HOME Inventory (Bradley \& Caldwell, 1979; Caldwell \& Bradley, 1984). The HOME (Home Observation and Measurement of the Environment) is a standardized interview-and-observation tool that assesses the quantity and quality of stimulation available to a child in its home environment. Administered by trained researchers (usually health professionals), the assessment takes the form of a home interview with the caregiver and index child present. The interviewer asks a set of questions about the child's 'typical' day and in conjunction with more general observation, scores the mother-child dyad on the presence versus absence of forty-five key responses and behaviors (for example, 'mother responds to child's vocalizations with a verbal response'). Six sub-scale scores are produced: verbal and emotional responsivity; acceptance of sub-optimal behavior; degree of organization of the child's temporal and physical environment; provision of learning materials; active involvement in learning; and inclusion of variety in the child's life. A higher score indicates a 'better' environment, i.e. one that is richer in terms of quality and/or quantity of stimulation In keeping with many studies, this paper considers the overall total score, i.e. the sum of all sub-scales, as an outcome.

The second outcome measure derives from another standardized, validated instrument - the Edinburgh Postnatal Depression Scale (EPDS; Cox, Holden, \& Sagovsky, 1987). This instrument is widely used as a screening tool for suspected postpartum depression. Participants indicate their strength of agreement with ten mood-related statement (for example, 'I have looked forward with enjoyment to things') and receive a total score ranging from 0-30, where a higher score means 'more depressive symptoms.' In this study, we used a dichotomized 
measure based on the advisory threshold score for clinical action: a score of 13 or greater was coded as ' 1 .' It is to be stressed that the EPDS is a screening tool and scores exceeding this threshold do not equate to a formal diagnosis of depression. However, validation studies suggest that a threshold set at this value correctly identifies around two-thirds of depressed women (Murray \& Carothers, 1990). The instrument also has good psychometric properties: in this study, preliminary analysis indicated high internal reliability for constituent items (Cronbach's alpha $=$ .89).

The final outcome used here is a dichotomized mother-report measure derived from a six-month survey item. Dental registration indicates whether the child is registered with a community dentist at six months ('yes' $=1$; 'no' or 'don't know' $=0$ ). As this is a mother-reported measure, it awaits validation from routine data sources.

\section{Baseline Predictor Variables}

A general aim of the quasi-experimental study is to explore the effects of the preventive intervention on child health while controlling for the many individualand household-level confounding factors. Accordingly, many such variables were included in the baseline survey, virtually all of which have been used in exploratory multivariate analysis. A full list of measures with appropriate references can be obtained from the communicating author, but the main sets of baseline predictors include: survey items relating to basic maternal and child data (child's gender, gestation, birth weight, feeding and behavior, parity, mother's age, etc); items covering maternal health and health behavior adapted from the 1998 Scottish Health Survey (Scottish Executive, 1998) and 2000 Scottish Crime Survey (Scottish Executive, 2002); the Rosenberg Self-Esteem Scale (Rosenberg, 1965); the DUKE-UNC Functional Support Scale (Broadhead, 1988); questions on attitudes to parenting and health-visiting; and items taken from the 2001 UK Decennial Census, for example highest maternal qualification, household employment, tenure and car ownership.

Baseline socio-economic status was constructed from employment-related survey items using the reduced 2001 National Statistics Socio-Economic Classification system (NS-SEC; Office of National Statistics, 2002). Some analytic classes were merged due to low counts, resulting in the following four dichotomized variables: NS-SEC class $1 \& 2$ (professional, managerial and higher technical occupations); NS-SEC classes 3, $4 \& 5$ (intermediate, lower supervisory and technical occupations); NS-SEC $6 \& 7$ (routine and semi-routine occupations); NS-SEC class 8 (never worked \& long-term unemployed).

Material circumstances were indexed via a self-report measure of household income (after tax). This ordinal measure (participants ticked one of nine income bands, e.g., ' $£ 200-299$ ’) was recoded into three dichotomized variables: 
lower income ( $<£ 400 /$ month); medium income (£400-£999/month) and higher income ( $>£ 1000 /$ month).

Service input was measured by collecting individual-level routine data on the number and type of contacts (including failed contacts) with health visitors and associated professionals. These data were collated from an operational database in the intervention area and from health visitor notes in the comparison area. While a number of measures could be constructed, problems of comparability across cohorts meant that only one-the total number of recorded home visits to six months-was used in analysis. This measure is likely to be the most reliable as health visitors and associated staff are the only health professionals to have face-to-face contact in the client's home. The mean number of such visits in the intervention area was 9.14 (standard deviation $=4.21$; range $=0-24$ ) compared to 3.46 (standard deviation $=2.32$; range $=0-16$ ) in the comparison area. Although these figures confirm the more intensive and home-based nature of the intervention, reference to both standard deviations and the range suggests considerable variation in the number of visits; evidently both types of service have the capacity to be flexible.

Finally, in order to test for intervention effects, intervention status was entered into analysis as a property of each individual family (i.e., intervention family coded as ' 1 ,' comparison family as ' 0 ').

\section{Statistical Approach}

Stepwise ordinary least-squares (OLS) regression was carried out with the total HOME score and logistic regression (method: Forward (Wald)) carried out with each dichotomous outcome variable. The process of modeling involved regressing blocks of cognate variables (for example, those measuring aspects of material circumstance) on the relevant outcome variable while controlling for key predictors (mother's age and ethnicity, parity and child's gender). Variables retained in each reduced model were entered into the final model, with intervention status 'forced' where it was not retained at an earlier stage. Overall, we have tried to produce a robust model that satisfies three modeling criteria: a priori reasoning; statistical significance; and parsimony in the number of variables retained in the final equation.

\section{RESULTS}

\section{Descriptive Statistics}

Table $\mathrm{V}$ shows descriptive statistics for the three six-month outcomes. HOME score means are similar with a (non-significantly) higher mean recorded for the comparison group. Comparisons of these descriptive statistics with previous 
Table V. Comparative Descriptive Statistics for Three Outcomes at Six Months

\begin{tabular}{lllcccc}
\hline & $\begin{array}{c}\text { Comparison } \\
(n=146)\end{array}$ & $\begin{array}{c}\text { Intervention } \\
(n=213)\end{array}$ & Difference & lower & upper & $p$ \\
\hline $\begin{array}{c}\text { HOME score } \\
\text { Mean (SD) }\end{array}$ & $35.4(4.1)$ & $34.5(5.1)$ & .94 & -.06 & 1.94 & .07 \\
$\begin{array}{c}\text { EPDS } \\
\% \text { scoring 13 } \\
\quad \text { or greater }\end{array}$ & 16.4 & 16.4 & $0 \%$ & $-8.1 \%$ & $7.6 \%$ & - \\
$\begin{array}{c}\text { Dental registration } \\
\% \text { children } \\
\text { registered }\end{array}$ & 26.0 & 45.1 & $19.1 \%$ & $9 \%$ & $28.3 \%$ & $<0.001$ \\
\hline
\end{tabular}

studies are difficult due to wide variation in the nature and needs of the samples studied. The proportion of mothers scoring 13 or greater on the EPDS is identical across cohorts at $16.4 \%$. This figure compares to a more general prevalence of $10-15 \%$ of women formally diagnosed with postnatal depression in the months immediately after birth (Cooper \& Murray, 1998). Given that the majority of cases spontaneously remit within two to six months, however (O'Hara, 1997), a prevalence of $16.4 \%$ at six months may be considered to be relatively high

A significantly greater proportion of intervention children were reported to be registered with a dentist. Comparable national figures are difficult to obtain, however, in 2002, around one third of all children aged 0-2 years were registered with a practitioner (National Health Service Scotland, 2003).

\section{Multivariate Analysis}

\section{Total HOME Score}

The results of stepwise OLS regression with total HOME score are shown in Table VI. The parameters in the table indicate a positive association between that predictor and the outcome unless there is a negative sign, in which case, the relationship is inverse.

No obvious intervention effect was observed as indicated by the fact that the relevant predictor parameter ('group' in the table) was not statistically significant when entered into the final model. However, a variety of child, maternal, and household factors were significantly associated with HOME score. Across cohorts, older mothers, mothers with fewer children or with higher self-esteem tended to achieve higher scores. Minority ethnic status was strongly and negatively associated with the HOME, indicating at face value a less stimulating home environment among this group. Families living in households with a higher relative income ( $>£ 1000$ per month, after tax) also tended to have higher scores. Finally, an investigator effect was observed: controlling for other baseline characteristics, 
Table VI. OLS Regression of Total HOME Score: Variables Retained in the Final Model

\begin{tabular}{lrccc}
\hline & Beta & SE (beta) & Standardized beta & $p$ \\
\hline Minority ethnic status & -6.82 & .80 & -.42 & $<.001$ \\
Higher household income & 2.42 & .47 & .24 & $<.001$ \\
Self-esteem & .14 & .05 & .13 & .006 \\
Research nurse A & 1.61 & .47 & .16 & .001 \\
Mother's age & .14 & .04 & .19 & $<.001$ \\
Number of children at home & -.76 & .20 & -.18 & $<.001$ \\
Group (intervention) & .34 & .46 & -04 & .45 \\
Constant & 28.52 & 1.33 & & $<.001$ \\
$\bar{N}=315$ & & & &
\end{tabular}

$\bar{N}=315$

Adjusted R-squared $=.38$

one of the three Research Nurses administering the HOME consistently scored families higher. The final model accounted for $38 \%$ of the variance in HOME scores.

\section{EPDS 'Caseness'}

The second and third columns of Table VII summaries the results of logistic regression analysis for women at risk of postnatal depression (EPDS scores of 13 or greater). Here, the key parameter is the odds ratio (OR). An OR of greater than one indicates a positive relationship between that predictor and the outcome; conversely an OR of less than one indicates a negative relationship.

In contrast to the HOME results, a statistically significant intervention effect emerged for women at risk of postnatal depression; controlling for background characteristics, women receiving the intervention were less likely to score above this threshold at six months. Minority ethnic women, however, were more likely to score above the threshold as were mothers whose children had been admitted to a special care baby unit, usually as a consequence of prematurity. In keeping with previous studies, psychosocial factors emerged as significant predictors: women with higher baseline self-esteem were less likely to report depressed mood whereas previous experience of mental health problems greatly increased the odds of a high EPDS score. Two measures of material (dis)advantage predicted risk of depression: higher relative household income (a negative association) and being in debt (a positive association). Across both cohorts, the total number of home visits by health professionals emerged as a significant positive predictor of outcome, which may indicate that staff had identified the depressed mood and increased levels of support. Finally, women who perceived there to be higher levels of informal social control in the neighborhood-neighbors more willing to intervene in minor acts of public disorder-were less likely to score above the EPDS threshold. 
Table VII. Summary of Odds Ratios for Logistic Regression of two Dichotomous Outcomes: Variables Retained in Final Models

\begin{tabular}{|c|c|c|c|c|}
\hline \multirow[b]{2}{*}{ Predictor } & \multicolumn{2}{|c|}{$\begin{array}{l}\text { Mother's EPDS } \\
\text { score } 13 \text { or greater }\end{array}$} & \multicolumn{2}{|c|}{$\begin{array}{l}\text { Child registered } \\
\text { with a dentist }\end{array}$} \\
\hline & Odds ratio & $p$ & Odds ratio & $p$ \\
\hline Minority ethnic status & 7.38 & .001 & 0.36 & .022 \\
\hline In $\operatorname{SCBU}^{a}$ (yes) & 4.34 & .002 & 1.95 & .047 \\
\hline Self-esteem & 0.86 & $<.001$ & & \\
\hline Previous mental health problems & 7.08 & $<.001$ & & \\
\hline Higher household income & 0.40 & .039 & & \\
\hline In debt (yes) & 2.45 & .021 & & \\
\hline In NS-SEC ${ }^{b}$ class 8 & & & 0.46 & .004 \\
\hline $\begin{array}{l}\text { Perceived levels of informal } \\
\text { social control in area }\end{array}$ & 0.92 & .030 & & \\
\hline Number of home visits & 1.14 & .006 & & \\
\hline Group (intervention) & 0.23 & .002 & 2.60 & $<.001$ \\
\hline$N=$ & & 343 & & 343 \\
\hline
\end{tabular}

Note. As EPDS caseness is an 'undesirable' outcome and dental registration a 'desirable' one, the direction and meaning of associations must be interpreted carefully.

${ }^{a}$ Special Care Baby Unit (intensive care unit for premature babies).

${ }^{b}$ National Statistics Socio-Economic Classification.

\section{Dental Registration}

The final two columns of Table VI summaries the results for logistic regression with dental registration status. A significant intervention effect was also found for this outcome: controlling for baseline characteristics, more Starting Well mothers reported that they had registered their children at the local dentist. Ethnicity again emerged as a very strong predictor with minority ethnic mothers only one-third as likely to register their children with a dentist. In contrast to EPDS caseness, having spent time in a special care baby unit was positively associated with dental registration. Finally, household-level material characteristics were again important for predicting outcome with children from families classified as 'never worked or long-term unemployed' (NS-SEC class 8) less likely to be registered with a dentist.

\section{DISCUSSION}

\section{Evidence for Preventive Intervention Effects}

This paper has assessed the evidence for preventive intervention effects on a range of health indicators over the first six months of the child's life. Two intervention effects were observed: more Starting Well children were registered with a dentist at six months and their mothers were less likely to be at risk of postnatal depression. At face value, these findings are undoubtedly encouraging 
and suggest that both psychological functioning and health-related behavior can be modified by an enhanced home visiting service over a relatively short period of time. Some care is needed, however, in the interpretation of findings.

Beginning with postnatal depression, the results support a number of studies showing the positive impact of home-based preventive interventions delivered by trained health visitors (Gerrard, Holden, Elliot, McKenzie, \& Cox, 1993; Holden, Sagovsky, \& Cox, 1989; Seeley, Murray, \& Cooper, 1996). In this study, the fact that an intervention effect emerged despite the cohorts having an apparently identical proportion of 'at-risk' women underlines the importance of including relevant statistical controls in analysis; there were fewer 'at risk' women in the intervention group at six-months than would be predicted from their background characteristics. To the extent that these findings are reliable ('caseness' does not always equate to 'disorder'), the clinical implications are clear: given the strong links between postnatal mood disorders and impaired child cognitive and emotional development (Murray, 1992; Murray, Fiori-Cowley, Hooper, \& Cooper, 1996), Starting Well is likely to deliver both immediate benefits to the depressed mother and more enduring benefits to the child. The practical, service-development implications are perhaps less straightforward, however, as is not clear from these results, what aspect(s) of the intervention produced the observed effect. Most preventive intervention studies focus exclusively on postnatal depression and involve dedicated training in non-directive counseling techniques whereas Starting Well has a much broader health focus and improves maternal mood without comparable training. One candidate for the 'active' ingredient may be the quality of the mother-health visitor contacts (Korfmacher, Kitzman, \& Olds, 1998). Elkan and colleagues (2000), in a review of British health visitors' degree theses, conclude that contacts that are non-controlling, non-judgmental and sensitive to the mother's agenda contribute to effectiveness in the management of postnatal depression. Some support for this comes from the case-study component of the present evaluation, specifically from depressed women's statements of what aspects of the health visitors' approach they found helpful. These statements are instructive but lack a comparative element as women from the comparison group were not interviewed. At this stage then, findings are only supportive of a "whole package' effect of the intervention on depressive symptoms, but future work in this area might concentrate on more detailed description of the interactions and relationships of health visitors and their clients.

Finally, our findings support previous studies in that experience of perinatal complications (indexed here by stay in a special care baby unit) and/or previous mental health problems, emerged as risk factors for a high EPDS score (see Murray \& Cartwright, 1993; O’Hara, Schlechte, Lewis, \& Varner, 1991).

Moving onto the dental registration finding, Scottish dental health statistics are stark: only one-third of children aged 0-2 are registered with a dentist (National Health Service Scotland, 2003) and by age five, 55\% of children have dental disease (Scottish Executive, 2003). Marked social gradients are observed 
for both registration and outcomes (Davies, 1999). While little prospective data are available on the association of early dental registration with later oral health, a recent cross-sectional study of Scottish five year olds showed that lower levels of dental caries were associated with dental registration status (Pitts, 1997). If this association holds, the practical significance of the observed intervention effect will depend firstly on the reliability of the mother-report measure and secondly, on the stability of registration status which will lapse if the child does not attend regularly. If results can be replicated using routine data and the observed differences in early registration can be sustained in the longer-term, then a real and lasting difference could be made to children's oral health. Longitudinal comparisons of actual dental attendance and outcomes are necessary to test this proposition. As a corollary, a recent qualitative study of parents of pre-school children in three Scottish Health Boards (including Greater Glasgow) described the many perceived barriers to registration, including confusion as to the appropriate age to do so, parental fear, hostile attitudes to staff, accessibility issues and lack of information and incentives to attend (Morrison, Macpherson, \& Binnie, 2000). Future qualitative work might explore the extent to which the observed gains in intervention areas are attributable to challenging these attitudes.

An intervention effect did not emerge for total HOME score. This was not entirely unexpected: meta-analyses and other reviews (Bradley, 1993; Elkan et al., 2000) suggest that home visiting programs can improve the quality of the home environment but as most studies refer to North American randomized control trials, often with children at different ages, or from particular high-risk groups, they are not strictly comparable to Starting Well. Moreover, of the studies making assessments at or around six months, some (e.g., Field, Widmeyer, Greenberg, \& Stoller, 1980; Larson, 1980) find significant intervention effects, while others (Osofsky, Culp, \& Ware, 1988; Wasik, Ramey, Bryant, \& Sparling, 1990) do not. In order to more fully explore this area, future work might usefully compare relative rates of improvement in HOME scores between six- and eighteen-month assessments as well as conducting further cross-sectional analyses.

\section{Associations Between Outcomes and Other Predictors}

Two sets of variables especially merit further comment: material (dis) advantage and ethnicity.

\section{Material (dis)advantage}

The last two decades have witnessed an explosion of multi-disciplinary research into health inequalities and their relationship to income and social status. Our findings support this literature in two ways. Firstly, both cohorts are disadvantaged in terms of their absolute material resources and display correspondingly 
high levels of adverse health and other behavior (e.g., maternal smoking). Secondly, families' relative position within this cohort, in terms of available material resources, is robustly and consistently associated with each outcome. These findings, while unsurprising, point to the relatively limited potential of health services to have an impact on the health of deprived populations when unaccompanied by improved material circumstances.

\section{Ethnicity}

Minority ethnic status was strongly associated with lower HOME scores, higher EPDS scores and lower rates of dental registration. These findings, if true, would offer a very poor prognosis for children of this background, however, they may be due to systematic measurement error as opposed to real health-relevant cultural practices. The HOME has been widely used in different cultures and languages (see Bradley, Colwyn, \& Whiteside-Mansell, 1996 for a review) but has never been validated on a British Asian cohort and the authors of the instrument admit that additional work is necessary in order to establish its cross-cultural validity (Bradley, 1993). Similarly, there are well-recognized problems with the translation of concepts relating to depression (Launguni, 1997; 2000) and with the EPDS in particular (Elliott, 1996; Gerrard, 2000), which have motivated recent work on a Punjabi version (Clifford et al., 1999) as well as alternatives using culturally appropriate concepts (Mantle, 2003). Measurement error is, perhaps, a less convincing explanation of lower dental registration rates; not only is this item a much simpler concept constructed from a response to a single survey item, the finding also supports other studies of infant feeding and dental health among British Asian populations (see Watt, 2000).

In summary, the findings most probably reflect both measurement issues and real cultural differences and illustrate the need for culturally sensitive assessment tools and culturally competent health workers of the type being piloted in Starting Well.

\section{Limitations and Next Steps}

\section{Instrumentation}

There is a clear need to repeat the dental registration analysis using routine data in order to account for possible misunderstanding and social desirability bias in response. Secondly, more sensitive and comparable indicators of service input are required, including perhaps, contacts with health staff that are not recorded by the index health visitor. It would also be advantageous to develop an equivalent measure of input that ascribed different weightings to different types of contact. This would mean, for example, that a ninety-minute face-to-face home visit from a 
health visitor is accorded considerably more importance than a five-minute phone contact from a lay worker. Thirdly, more work is required on research nurse interrater reliability in order to account for the observed investigator effect on HOME score. Fourthly, the cultural specificity of both the HOME and EPDS necessitates careful interpretation of results, and may benefit from separate analyses, although numbers are small.

\section{Development of the Project}

Starting Well, as one of the National Health Demonstration Projects, is a test-bed for practice innovation and while it is strongly evidence-based, practical constraints of time and resources mean that service delivery and development have occurred simultaneously. In some key senses, the service 'package' offered to families who were recruited into the evaluation in mid-2001 was more limited than that offered to families recruited one year later (for example, only the very last families to be recruited will have been attended by the full 'skill mix' team including paraprofessionals and nursery nurses). This within-intervention variability in service may dilute intervention effects if the full, 'mature' service is better placed to deliver health improvements. This possibility could be examined by recruiting and monitoring a second cohort of families who have only received the 'mature' service.

\section{Bias and Attrition}

A number of factors have contributed to the relatively small sample analyzed in this paper, most of them reflecting the inherent challenges of conducting longitudinal research in areas of multiple deprivation. While we believe recruitment via health visitor secured a much higher opt-in rate than an approach from a researcher, families, often with complex needs, were asked to commit to a long-term study very soon after the birth of their child. That this is a trying time is supported by 'reason for refusal' forms that indicate around 75\% of opt-outs (both cohorts) were either 'too busy' or 'too tired.' Less than 5\% had unassuagable concerns about privacy. Similar reasons have been cited in more systematic studies of families declining to take part in health-visiting trials (Barlow, Kirkpatrick, Stewart-Brown, \& Davis, 2003).

Attrition due to moving has also been constant and completion rates have been imperfect due to a high number of broken appointments with research nurses. Finally, even families that have remained in the study have not always been contactable at both baseline and six-month assessments and could not therefore be included in this paper. ${ }^{4}$ Clearly, opt-in and completion bias must be accounted

\footnotetext{
${ }^{4}$ Some 'background' data (including data gathered retrospectively at the six-month assessment) exists on 452 participants. Confirmatory analysis using reduced models will be carried out on this dataset as a priority.
} 
for: these issues are high priority for future analysis and will be explored using aggregate routine health data on opt-outs.

\section{CONCLUSION}

This paper has presented early results from the evaluation of an evidencebased, intensive home visiting preventive intervention aimed at improving the health of children in disadvantaged communities. Multivariate analysis of three disparate outcomes at six-months indicated positive evidence of intervention effects for both child dental registration status and maternal psychological functioning. To the extent that they are generalizable, these findings suggest that children receiving Starting Well may enjoy long-term benefits in terms of better oral health and protection against developmental delay, although more work is needed in order to understand the mechanisms by which the program achieves its effects. In addition, ethnicity and background characteristics relating to material resources emerged as important independent predictors of outcome. These and other findings will be re-visited at the eighteen-month follow-up assessment but in the meantime further work is required in terms of the validation of key measures, checking for both response and opt-in bias and controlling for the development of the intervention itself. The full evaluation of this project is continuing.

\section{ACKNOWLEDGMENTS}

The authors gratefully acknowledge the funding provided by the Health Improvement Strategy Division of the Scottish Executive Health Department. We would also like to thank colleagues who provided comments on versions of this paper, including Harper Gilmour, Ron Gray, John Norrie, Mhairi Mackenzie, David Stone, Peter Craig, Kathryn Berzins and Linda de Caestacker. Finally, we would like to acknowledge the fieldwork team of Sheena Mitchell, Margaret Baillie, Eileen Duff and Veronica Smith and those involved in training and advising them, particularly Christine Puckering and Tony Cox.

\section{REFERENCES}

Barlow, J., Kirkpatrick, S., Stewart-Brown, S., \& Davis, H. (2003). 'Hard-to-reach' or 'out-of-reach' : Reasons why vulnerable women refuse to take part in interventions designed to help and trials to assess their impact (working paper). University of Oxford, Health Services Research Unit, Institute of Health Sciences, Department of Public Health.

Bradley, R. H. (1993). Children's home environments, health, behavior and intervention efforts: A review using the HOME Inventory as a marker measure. Genetic, Social and General Monographs, $119(4), 439-491$.

Bradley, R. H., \& Caldwell, B. M. (1979). Home observation and measurement of the environment: A revision of the preschool scale. American Journal of Mental Deficiency, 84, 235-244. 
Bradley, R. H., \& Caldwell, B. M. (1988). Using the HOME Inventory to assess the family environment. Pediatric Nursing, 14, 97-102.

Bradley, R. H., Colwyn, R. F., \& Whiteside-Mansell, L. (1996). Life at home: Same time, different places-an examination of the HOME inventory in different cultures. Early Development and Parenting, 5(4), 251-269.

Broadhead, W. E. (1988). The Duke-UNC Functional Social Support Questionnaire. Medical Care, 26(7), 709-721.

Bull, J., McCormick, G., Swann, C., \& Mulvihill, C. (2004). Evidence briefing summary: Ante- and post-natal home visiting programs: A review of reviews. London: Health Development Agency.

Caldwell, B. M., \& Bradley, R. H. (1984). Home observation and measurement of the environment. Little Rock, AR: University of Arkansas at Little Rock.

Clifford, C., Day, A., Cox, J., \& Werrett, J. (1999). A cross-cultural analysis of the use of the Edinburgh Postnatal Depression Scale in health visiting practice. Journal of Advanced Nursing, 30(3), 655664.

Connell, J. P., \& Kubisch, A. C. (1998). Applying a theory of change approach to the evaluation of comprehensive community initiatives: Progress, prospects and problems. In A. FulbrightAnderson, A. C. Kubisch, \& J. P. Connell (Eds.), New approaches to evaluating community initiatives: Theory, measurement and analysis (pp. 15-44). Washington, DC: Aspen Institute.

Cooper, P. J., \& Murray, L. (1998). Postnatal Depression. British Medical Journal, 316, 1884-1886.

Cox, J. L., Holden, J. M., \& Sagovsky, R. (1987). Detection of postnatal depression: Development of the 10-item Edinburgh Postnatal Depression Scale. British Journal of Psychiatry, 150, 782-786.

Davies, J. A. (1999). Enhancing dental attendance rates for children from deprived areas in the UK. British Dental Journal, 187(6), 323-326.

Elliott, S. (1996). A model of multi-disciplinary training on the management of postnatal depression. In Postnatal depression: focus on a neglected issue. Papers from the HVA/NCT national conference, London, 18 April 1996. London: Health Visitors' Association/National Childbirth Trust.

Elkan, R., Kendrick, D., Hewitt, M., Robinson, J. J. A, Tolley, K., Blair, M., et al. (2000). The effectiveness of domiciliary health visiting: A systematic review of international studies and a selective review of the British literature. Health Technology Assessment, 4, 13.

Field, T. M., Widmayer, S. M., Greenberg, R., \& Stoller, S. (1980). Effects on parent training on teenage mothers and their infants. Pediatrics, 69, 703-707.

Fulbright-Anderson, A., Kubisch, A. C., \& Connell, J. P. (Eds.). (1998). New approaches to evaluating community initiatives: Theory, measurement and analysis. Washington, DC: Aspen Institute.

General Register Office (Scotland). (2003). Scottish census results on-line (SCROL). Retrieved August 14, 2003 from http://www.scrol.gov.uk/scrol/common/home.jsp.

Gerard, J., Holden, J., Elliott, S., McKenzie, P., \& Cox, J. (1993). A Trainer's perspective of an innovative program teaching health visitors about the detection, treatment and prevention of postnatal depression. Journal of Advanced Nursing, 18, 1825-1832.

Gerrard, J. (2000). Postnatal Depression. London: Emap Healthcare.

Holden, J., Sagovsky, R., \& Cox, J. (1989). Counseling in a general practice setting: A controlled study of health visitor intervention in treatment of postnatal depression. British Medical Journal, 298, 223-226.

Judge, K., \& Bauld, L. (2001). Strong theory, flexible methods: Evaluating complex community-based initiatives. Critical Public Health, 11(1), 19-38.

Judge, K., \& Mackenzie, M. (2002). Theory-based evaluation: New approaches to evaluating complex community-based initiatives. In J. Mackenbach \& M. Bakker (Eds.), Reducing Inequalities in Health: A European Perspective (pp. 300-312). London: Routledge.

Kitzman, H., Olds, D., Henderson, J., Hanks, C., Cole, R., \& Tatelbaum, R. (1997). Effect of prenatal and infancy home visitation by nurses on pregnancy outcomes, childhood injuries and repeated childbearing. Journal of the American Medical Association, 278, 644-652.

Korfmacher, J. Kitzman, H., \& Olds, D. (1998) Intervention processes as predictors of outcomes in a preventive home-visitation program. Journal of Community Psychology, 26(1), 49-64.

Larson, C. P. (1980). Efficacy of prenatal and postpartum home visits on child and health development. Pediatrics, 66, 191-1977.

Launguni, P. (1997). Mental illness in India and Britain: Theory and practice. Medical Law, 16, 509-540. 
Launguni, P. (2000). Postnatal depression across cultures: Conceptual and methodological considerations. International Journal of Health Promotion \& Education, 38(3), 86-94.

Mantle, F. (2003). Developing a culture-specific tool to assess postnatal depression in the Indian community. British Journal of Community Nursing, 8(4), 176-180.

Morrison, J. J., Macpherson, L. M. D., \& Binnie, V. I. (2000). A qualitative investigation of the perceived barriers to and inducements for the early registration of infants with general dental practitioners. International Journal of Health Promotion and Education, 38(1), 4-9.

Murray, L. (1992). The impact of postnatal depression on infant development. Journal of Child Psychology and Psychiatry, 33, 543-561.

Murray, L., \& Carothers, A. D. (1990). The validation of the Edinburgh Postnatal Depression Scale on a community sample. British Journal of Psychiatry, 157, 288-290.

Murray, L., \& Cooper, P. J. (1997). Postpartum depression and child development. Psychological Medicine, 27, 253-260.

Murray, L., \& Cartwright, W. (1993). The role of obstetric factors in postpartum depression. Journal of Reproductive and Infant Psychology, 11, 215-219.

Murray, L., Fiori-Cowley, A., Hooper, R., \& Cooper, P. J. (1996). The impact of postnatal depression and associated adversity on earlier mother-infant interactions and later infant outcomes. Child Development, 67, 2512-2526.

National Children's Homes Scotland. (2002). Factfile 2002: Facts and figures about Scotland's children, London: NCH.

National Health Service Scotland, Information and Statistics Division. (2003). Scottish health statistics. Retrieved August 14, 2003 from http://www.show.scot.nhs.uk/isd/

Office of National Statistics. (2002). The national statistics socio-economic classification user manual. London: The Stationery Office.

O'Hara, M. W. (1997). The nature of postpartum depressive disorders. In L. Murray \& P. J. Cooper (Eds.), Postpartum Depression and Child Development (pp. 3-31). New York: Guilford.

O’Hara, M. W., Schlechte, J. A., Lewis, D. A., \& Varner, M. W. (1991). A controlled prospective study of postpartum mood disorders: Psychological, environmental and hormonal variables. Journal of Abnormal Psychology, 100, 63-73.

Olds, D. L., Eckenrode, J., Henderson, C. R. Jr., Kitzman, H., Powers, J., Cole, R., et al. (1997). Long-term effects of home visitation on maternal life course and child abuse and neglect: 15-year follow-up of a randomized trial. Journal of the American Medical Association, 278(8), 637-643.

Olds, D. L., Henderson, C. R. Jr., Cole, R., Eckenrode, J., Kitzman, H., Luckey, D., et al. (1998). Longterm effects of nurse home visitation on children's criminal and antisocial behavior: 15-year follow-up of a randomized control trial. Journal of the American Medical Association, 280(14), 1238-1244.

Osofsky, J. D., Culp, A. M., \& Ware, L. M. (1988). Intervention challenges with adolescent mothers and their infants. Psychiatry, 51, 236-241.

Pitts, N. B. (1997). Do we understand which children need and get the appropriate dental care? British Dental Journal, 182, 273-278.

Ray, K. L., \& Hodnett, E. D. (1997). Caregiver support for postpartum depression (Cochrane Review). Chichester, UK: John Wiley \& Sons Ltd.

Rosenberg, M. (1965). Society and the adolescent self-image. Princeton, NJ: Princeton University Press.

Sanders, M. R. (1999). The Triple P-Positive Parenting Program: Towards an empirically validated multilevel parenting and family support strategy for the prevention of behavior and emotional problems in children. Clinical Child and Family Psychology Review, 2, 71-90.

Scottish Executive Central Research Unit. (2002). The 2000 Scottish crime survey. Edinburgh: The Stationery Office.

Scottish Executive Health Department. (2000). The 1998 Scottish health survey. Edinburgh: The Stationery Office.

Scottish Executive Health Department. (2003). National health demonstration projects. Retrieved September 29, 2003 from http://www.show.scot.nhs.uk/demonstrationprojects

Scottish Executive. (2003). Towards better oral health in children: A consultation document on children's oral health in Scotland. Retrieved August 15, 2003 from http://www.scotland. gov.uk/consultations/health/ccoh-03.asp 
Seeley, S., Murray, L., \& Cooper, P. J. (1996). Health visitor intervention in postnatal depression. An evaluation of the outcome for mother and babies. Health Visitor, 69(4), 135-238.

Shapiro, C. (1995). Shortened hospital stay for low-birth-weight infants: Nuts and bolts of a nursing intervention project. Journal of Obstetric, Gynecologic and Neonatal Nursing, 24(1), 56-63.

Sharp, D., Hay, D., Paulby, S., Shmacher, G., Allen, H., \& Kumar, R. (1995). The impact of postnatal development on boys' intellectual development. Journal of Psychology and Psychiatry, 36(13), $1315-1337$.

Wasik, B. H., Ramey, C. T., Bryant, D. M., \& Sparling, J. J. (1990). A longitudinal study of two early intervention strategies: Project CARE. Child Development, 61, 1682-1696.

Watt, R. G. (2000). A national survey of infant feeding in Asian families: Summary of findings relevant to oral health. British Dental Journal, 188(1), 16-20. 